\title{
In-vitro Inhibitory Effects of Polyphenolic Extract of Ichnocarpus Frutescens on Carbohydrate Digestive Enzymes
}

\author{
Kumarappan Chidambaram ${ }^{1, *}$, Kumar Venketesan², Senthilrajan Dharmalingam ${ }^{3}$, \\ Rajinikanth Siddalingam $^{4}$, Thilagam Ellappan ${ }^{5}$, Subhash Chandra Mandal ${ }^{5}$ \\ ${ }^{1}$ Department of Pharmacology \& Toxicology, College of Pharmacy, King Khalid University, Saudi Arabia \\ ${ }^{2}$ Department of Pharmaceutical Chemistry, College of Pharmacy, King Khalid University, Saudi Arabia \\ ${ }^{3}$ Department of Pharmaceutics, Swamy Vivekanandha College of Pharmacy, India \\ ${ }^{4}$ Department of Pharmaceutical Sciences, School of Biomedical and Pharmaceutical Sciences, Babasaheb Bhimrao Ambedkar \\ University, India \\ ${ }^{5}$ Department of Pharmaceutical Technology, Phytotherapy Research Laboratory, Jadavpur University, India
}

Copyright $\mathrm{C} 2019$ by authors, all rights reserved. Authors agree that this article remains permanently open access under the terms of the Creative Commons Attribution License 4.0 International License

\begin{abstract}
Background: Ichnocarpus frutescens has been used as Ayurvedic herbal medicine by Gond tribes in India to treat several diseases such as diabetes mellitus and Jaundice. The growing incidence of diabetes mellitus and its complications have headed to the search of novel therapeutic approaches engrossed on preventing postprandial hyperglycemia. The practice of carbohydrate breakdown enzyme inhibitors from plant resources might be a potential approach to prevent glucose absorption with the least adverse effects. Aims: The objective of the present investigation was to provide in-vitro evidence for the potential inhibitory activity of polyphenolic extract (PPE) of Ichnocarpus frutescens on $\alpha$-amylase and $\alpha$-glucosidase enzymes. Methods: the in the vitro inhibitory effect of polyphenolic extract (PPE) of Ichnocarpus frutescens focused on the evaluation of pancreatic $\alpha$ - amylase inhibition, rat serum $\alpha$ - amylase inhibition and rat intestinal $\alpha$-glucosidase inhibition of polyphenolic extract (PPE) of Ichnocarpus frutescens by in vitro. The different concentrations of polyphenolic extract were subjected to $\alpha$-amylase and $\alpha$-glucosidase inhibitory assay and the percentage of $\alpha$ - amylase and $\alpha$ - glucosidase inhibitory activity and $\mathrm{IC}_{50}$ values were calculated. Results: Polyphenolic extract shows appreciable pancreatic $\alpha$ amylase inhibitory activity in vitro. The extract also showed an appreciable $\alpha$-glucosidase inhibitory effect in a concentration-dependent manner with a moderate $\alpha$-amylase inhibitory activity. The in vitro examination of the inhibitory effect of PPE on maltase and sucrase activities revealed that PPE inhibited rat small intestine disaccharidase ( $\alpha$-glucosidase) activity. Conclusion: Taken together, these results suggest that inhibitory effect of PPE on $\alpha$ - amylase and $\alpha$ - glucosidase activities may delay
\end{abstract}

carbohydrate digestion and absorption with subsequent lowering of blood glucose level leading to prevention of postprandial hyperglycemia in diabetes and its complication.

\section{Keywords Ichnocarpus Frutescens Extract, Carbohydrate Metabolism, $\alpha$-amylase, $\alpha$-glucosidase,} Diabetes Mellitus, Postprandial Hyperglycemia

\section{Introduction}

Hyperglycemia is a condition characterized by an abnormal excess of sugar in the blood. Chronic postprandial hyperglycemia is widely recognized as one of the earliest disease biomarkers in the prediction of subsequent microvascular and macrovascular complications that can progress to full symptomatic Type2 diabetes mellitus [1-2]. The frequency of diabetes in the population worldwide is high and still increasing. In the process of this metabolic disorder, concentrations of blood glucose and serum insulin differ from normal concentration, especially after food intake. While the majority of available synthetic antidiabetic drugs target the dual metabolic effects that characterize type II diabetes, impaired insulin secretion, insulin resistance, some of these drugs can have negative side effects at high doses [3-4]. An effective way to control these carbohydrate dependent diseases would be to limit the intestinal carbohydrate digestion.

Starch and sucrose account for $80 \%$ to $90 \%$ of our daily intake of carbohydrates. Small intestinal $\alpha$-glucosidase 
(EC.3.2.1.20) and pancreatic $\alpha$-amylase (EC.3.2.1.1) are key enzymes of dietary carbohydrate digestion in humans. Inhibitors of these enzymes may be effective in retarding carbohydrate digestion and reduce glucose absorption not to support postprandial hyperglycemia. Plants have been used to treat diabetes mellitus since ancient times. Studies to reveal the mode of action of potential anti-diabetic plants will definitely confer scientific and systematic approach to the use of these plants as hypoglycemic agents. Findings from recent clinical and preclinical studies suggest that plant derived-polyphenolic foods could become valuable treatment options for optimizing hyperglycemic control in diabetic patients. The relative efficacy of $\alpha$-amylase inhibitors in affecting human digestion or starch has been highlighted by recent publications [5].

$\alpha$-amylase and $\alpha$-glucosidase inhibitors are drug design targets for the developments of diabetes, obesity, and hyperglycemia [6]. Inhibitory activity against $\alpha$ - amylase, and glucosidase by polyphenols, flavonoids, and anthocyanins has been reported [7-8]. In addition, numerous $\alpha$-glucosidase and $\alpha$-amylase inhibitors have been screened from plants, some of which are of clinical importance [9-10]. $\alpha$-glucosidase inhibitors such as acarbose, miglitol, and voglibose are known to reduce postprandial hyperglycemia primarily by interfering with the carbohydrate digestive enzymes and delaying glucose absorption. Therefore, much effort has been focused on plants for potentially useful products as commercial $\alpha$ amylase and $\alpha$-glucosidase inhibitors.

Plants belonging to Apocynaceae family have been used for the common ailments as traditional medicine. Recent research has now indicated that these herbs are a rich source of phenolic phytochemicals having high antioxidant activity. Phenolic phytochemicals are now implicated to have the potential for the management of many chronic diseases such as diabetes and cardiovascular diseases [11]. Consequently, Ichnocarpus frutescens has gained prominence as a functional food for the treatment of diabetes among tribals of several Indian regions [12]. The health-promoting effects of I.frutescens are thought to be related to the high polyphenolic content. Distribution of various flavonoids and phenolic acids in the leaves of Ichnocarpus frutescens have been systematically studied [13]. In the present study, the polyphenolic extract (PPE) of the I.frutescens was examined for its invitro inhibitory effect on rat intestinal $\alpha$ - glucosidase, $\alpha$ - amylase (Porcine Pancreatic amylase) and rat serum $\alpha$ - amylase activities.

\section{Materials and Methods}

\subsection{Chemicals}

$\alpha$-amylase, folin-ciocalteu reagent, precoated with silica gel $60 \mathrm{~F}_{254}, p$-anisaldehyde reagent, fast blue $\mathrm{B}$ salt, pyrocatechol, starch, dinitrosalicylic acid colour reagent, 2-chloro-p-nitrophenyl- $\alpha$-D-maltotrioside (CNPG3), 2, 4 - dinitrophenylhydrazine, maltose, sucrose, naringenin, quercetin, pentobarbitone were purchased from Sigma Aldrich, Bangalore, India. All other chemicals and solvents of analytical grade were purchased from local.

\subsection{Plant Materials}

The fresh leaves of Ichnocarpus frutescens (L.) R.Br. recently were collected from Delta region of Cauvery River, Thiruchirappalli, India and was authenticated at Botanical Survey of India, Central National Herbarium, Howrah, India (REF NO: CNH/I-I/87-TECH/1326). An authentic voucher specimen was deposited in the Herbarium Division of Pharmacognosy, Department of Pharmaceutical Technology, Jadavpur University, Kolkata, India.

\subsection{Extraction of Polyphenols (PPE)}

Dried leaves of Ichnocarpus frutescens $(500 \mathrm{~g})$ were finely powdered, mixed with $70 \%$ methanol and kept at room temperature for 5 days. After 5 days it was filtered and the solvent was evaporated. The residue was dissolved in water and the aqueous layer was washed with petroleum ether several times until a clear upper layer of petroleum ether was obtained. The lower layer was then treated with ethyl acetate containing glacial acetic acid $(10 \mathrm{~mL} / \mathrm{L})$. Extraction of polyphenols was carried out for $36 \mathrm{~h}$ at room temperature and the combined ethyl acetate layer was concentrated. The residue was lyophilized and stored at $-70^{\circ} \mathrm{C}$. The total polyphenolic content and flavonoid of the extract were assayed using the standard methods.

\subsection{Animals and Ethical Approval}

Swiss albino mice (20 - 25g body weight) and Wistar albino rats (180 - 200g body weight) were used in the present study. Animals were collected from the breeding colony and acclimatized to the laboratory condition for 2 weeks. They were housed in macrolon cages under standard laboratory conditions (light period from 7.00 a.m. to 7.00 p.m., temperature $21 \pm 2^{\circ} \mathrm{C}$, and relative humidity 55-70\%). The animals were fed with commercial diet from Hindustan Lever Ltd (Bangalore, India) and free access to water (ad libitum) during the experiments.

\section{5. $\alpha$-amylase Inhibitory Activities}

\subsection{1. $\alpha$-amylase Inhibitory Assay by DNS Method (in vitro)}

Porcine pancreatic $\alpha$-amylase (EC 3.2.1.1) was purchased from Sigma Aldrich Chemical Co. A total of $500 \mu \mathrm{L}$ of PPE and $500 \mu \mathrm{L}$ of $0.02 \mathrm{M}$ sodium phosphate buffer $(\mathrm{pH}$ 6.9 with $0.006 \mathrm{M}$ sodium chloride) containing $\alpha$-amylase solution $(0.5 \mathrm{mg} / \mathrm{mL})$ were incubated at $25^{\circ} \mathrm{C}$ for $10 \mathrm{~min}$. After pre-incubation, $500 \mu \mathrm{L}$ of a $1 \%$ starch solution in 
$0.02 \mathrm{M}$ sodium phosphate buffer ( $\mathrm{pH} 6.9$ with $0.006 \mathrm{M}$ sodium chloride) was added to each tube at timed intervals. The reaction mixtures were then incubated at $25^{\circ} \mathrm{C}$ for $10 \mathrm{~min}$. The reaction was stopped with $1.0 \mathrm{~mL}$ of dinitrosalicylic acid colour reagent. The test tubes were then incubated in a boiling water bath for $5 \mathrm{~min}$, cooled to room temperature. The reaction mixture was then diluted by adding $10 \mathrm{~mL}$ distilled water and absorbance was measured at $540 \mathrm{~nm}$. The bioassay method was adopted and modified from Sigma Aldrich (www.sigmaaldrich.com).

\section{Inhibition $=$}

$$
\frac{\mathrm{Abs} \text { control }(540)-\mathrm{Abs} \text { extract }(540)}{\mathrm{Abs} \mathrm{s}_{\text {control }}(540)} \times 100 \%
$$

\subsection{2. $\alpha$-amylase Inhibitory Assay by $\mathrm{CNP}_{-} \mathrm{G}_{3}$ Method (in} vitro)

The ability of porcine pancreas $\alpha$-amylase to release 2-chloro-4-nitrophenol (CNP) from $\mathrm{CNP}_{-} \mathrm{G}_{3}$ was measured with a slight modification of the methods described previously [14]. A reaction mixture $(450 \mu \mathrm{L})$ consisting of $0.15 \mathrm{mM} \mathrm{CNP}_{-} \mathrm{G}_{3}$ and $0.2 \mathrm{M}$ potassium thiocyanate (KSCN) solution in $0.05 \mathrm{M}$ phosphate buffer $\mathrm{pH} 7.0$, and $30 \mu \mathrm{L}$ of different concentrations of PPE were pre-incubated for $5 \mathrm{~min}$ at $25^{\circ} \mathrm{C}$ followed by the addition of $20 \mu \mathrm{L}$ of freshly prepared $\alpha$-amylase solution $(1 \mathrm{mg} / \mathrm{mL})$ in phosphate buffer, $\mathrm{pH}$ 7.0. Liberation of CNP from $\mathrm{CNP}_{-} \mathrm{G}_{3}$ was determined by measuring the increase in absorbance at $405 \mathrm{~nm}$ during the reaction. The inhibitory activity $(\%)$ was calculated as $[(\mathrm{A}-\mathrm{B}) / \mathrm{A}] \times 100$, where $\mathrm{A}$ is the increase absorbance during the reaction mixture in the absence of PPE and $\mathrm{B}$ is that in its presence.

\subsection{3. $\alpha$-amylase Inhibitory Assay by Starch Iodine Method} (in vitro)

The activity $\alpha$-amylase was carried out according to the previously described method, based on starch-iodine colour changes with minor modification [15]. $0.1 \mathrm{~mL}$ of $\alpha$ amylase $(15 \mu \mathrm{g} / \mathrm{mL}$ in $0.1 \mathrm{M}$ acetate buffer at $\mathrm{pH} 7.2$ containing $0.0032 \mathrm{M}$ sodium chloride) was added to the mixture of $3 \mathrm{~mL}$ of $1 \%$ starch solution. The solution was kept in the refrigerator and was used within 3 days and 2 $\mathrm{mL}$ of acetate buffer $(0.1 \mathrm{M}, \mathrm{pH}$ 7.2) pre-equilibrated at $30^{\circ} \mathrm{C}$ in a water bath. The substrate and $\alpha$-amylase blank determinations were undertaken under the same conditions. At zero time $(\mathrm{t}=0 \mathrm{~min})$ and at the end of the incubation period $(\mathrm{t}=60 \mathrm{~min}), 0.1 \mathrm{~mL}$ of the reaction mixture was withdrawn from each tube after mixing and transferred into $10 \mathrm{~mL}$ of an iodine solution $(0.254 \mathrm{~g}$ iodine and $4.0 \mathrm{~g}$ potassium iodide in $1 \mathrm{~L}$ ). After mixing, the absorbance of the starch-iodine mixture was measured immediately at room temperature at $565 \mathrm{~nm}$.

\subsubsection{Inhibition of Rat Plasma $\alpha$-amylase Activity (invivo): Preparation of Rat plasma}

Male Swiss albino rats (4-6weeks) were maintained under standard environmental conditions with $12 \mathrm{~h}$ light and $12 \mathrm{~h}$ dark exposure. The animals were allowed free access to food and water. Investigations using experimental animals were conducted in accordance with internationally accepted principles of laboratory animal use and care. After overnight fasting, the rats were sacrificed and cardiac blood was collected from the rat with a heparin-treated cylinder and centrifuged at $5000 \times \mathrm{g}$ for $20 \mathrm{~min}$. The plasma was collected and stored at $4^{\circ} \mathrm{C}$ until further use.

\subsection{6. $\alpha$-amylase Assays in Rat Plasma}

$\alpha$-amylase activity was carried out according to the good-starch method [16]. Briefly, $0.5 \mathrm{~mL}$ of substrate buffer solution $(0.25 \mathrm{M}$ phosphate buffer at $\mathrm{pH} 7.0$ containing $40 \mathrm{mg} / \mathrm{dL}$ soluble starch) was mixed well with $0.10 \mathrm{~mL}$ of distilled water and kept at $37^{\circ} \mathrm{C}$ for $5 \mathrm{~min}$. this was done for both sample and blank. After the incubation period, $0.01 \mathrm{~mL}$ of rat plasma was added to the sample solution only and well mixed before being re-incubated at $37^{\circ} \mathrm{C}$ for $7.5 \mathrm{~min}$. after the second incubation time, $0.5 \mathrm{~mL}$ of colouring agent $(0.254 \mathrm{~g}$ iodine and $4.0 \mathrm{~g}$ potassium iodide in $1 \mathrm{~L}$ ) and $2.5 \mathrm{~mL}$ of distilled water were added. After mixing, the absorbance of the solution was measured at $560 \mathrm{~nm} .0 .1 \mathrm{~mL}$ of different concentration of the PPE solution was incubated with $0.5 \mathrm{~mL}$ of substrate buffer solution at $37{ }^{\circ} \mathrm{C}$ for $5 \mathrm{~min}$. Then the same procedure was adopted as above. The inhibitory activity (\%) was calculated by using the following formula: \% Inhibitory activity $=(1-\mathrm{A} / \mathrm{B}) \times 100$; Where $\mathrm{A}$ is the activity of the enzyme with PPE and B is the activity of enzyme solution without PPE.

\subsection{Mouse a-glucosidase Inhibitory Activity}

In order to investigate the inhibitory of PPE, an in vitro $\alpha$-glucosidase inhibition test was performed. $\alpha$-glucosidase from yeast is used extensively as a screening material for $\alpha$-glucosidase inhibitors, but the results do not always agree with that obtained in mammals. Therefore, we used the mouse small intestine homogenate as an $\alpha$-glucosidase solution because we speculated that it would better reflect the in vivo state. The inhibitory effect was measured using the method slightly modified from a previously described method [17]. After fasting for $20 \mathrm{~h}$, the small intestine between the part immediately below duodenum and the part immediately above the cecum was cut, rinsed with ice-cold saline, and homogenized with $12 \mathrm{~mL}$ of maleate buffer ( $100 \mathrm{mM}, \mathrm{pH} 6.0)$. The homogenate was used as the $\alpha$-glucosidase solution.

The assay mixture consisted of $100 \mathrm{mM}$ maleate buffer $(\mathrm{pH}$ 6.0), $500 \mathrm{mM}$ each sugar substrate (maltose and 
sucrose) solution $(100 \mu \mathrm{L})$, and different concentrations of PPE. It was preincubated for $5 \mathrm{~min}$ at $37^{\circ} \mathrm{C}$, and the reaction was initiated by adding the crude $\alpha$-glucosidase solution $(50 \mu \mathrm{L})$ to it, followed by incubation for $10 \mathrm{~min}$ at $37^{\circ} \mathrm{C}$. The glucose released into the reaction mixture was determined with the kit described above. The rate of carbohydrate decomposition was calculated as percentage ratio to the amount of glucose obtained when the carbohydrate was completely digested. The rate of prevention was calculated by the following formula: Inhibition rate $(\%)=($ Amount of glucose produced by the positive control) - (Amount of glucose produced by the addition of PPE) - (Glucose production value in the blank)/ (Amount of glucose produced by the positive control) $\times$ 100.

\subsection{Statistical Analysis}

The experimental data were expressed as mean \pm SEM. The significance of difference among the various treated groups and control group were analyzed by means of one-way ANOVA followed by Dunnett's multiple comparison tests using GraphPad Instat Software version 3.06 (San Diego, USA). $P<0.05$ was considered as statistically significant. $\mathrm{IC}_{50}$ (inhibitor concentration which produces $50 \%$ inhibition) were estimated using linear regression method of plots of the percent inhibitory activity against the concentration of the tested compounds using Microsoft Excel Software Programme (Microsoft Office 2010 version).

\section{Results and Discussion}

The aim of the study was to show the different reactivity of porcine pancreatic amylase and rat intestinal $\alpha$ glucosidase with different concentrations of polyphenolic extract (PPE). As shown in Fig. 1 incubation of PPE at different concentrations with pancreatic $\alpha$ - amylase enzyme caused a dose-dependent decrease in its activity with $50 \%$ inhibition $\left(\mathrm{IC}_{50}\right)$ at $42.91 \mu \mathrm{g} / \mathrm{ml}$ for the DNS method. Furthermore, the inhibitory activity of PPE against porcine pancreatic amylase was determined in vitro by $\mathrm{CNP}_{-} \mathrm{G}_{3}$ and starch iodine method (Fig. 1). These results show the anti-amylase activity of PPE equivalent phenolic basis, notably for the higher dose tested, the $\alpha$-amylase inhibitory activity was relatively high compared to other tested doses. Since PPE was found to inhibit in vitro, its activity was then studied using $\alpha$ - amylase in rat plasma in vivo. The results were depicted in Fig. 2. An increase in grade concentrations of the PPE and nojirimycin were found to inhibit rat plasma $\alpha$-amylase activity with $50 \%$ inhibition $\left(\mathrm{IC}_{50}\right)$ at $54.34 \mu \mathrm{g} / \mathrm{ml}$ for and $123.41 \mu \mathrm{g} / \mathrm{ml}$, respectively. PPE exhibited $\alpha$-glucosidase inhibitory (maltase and sucrase) activities in a dose-dependent manner (Fig 3). However, the inhibitory effect of PPE was weaker than that of acarbose, which is a well-known $\alpha$-glucosidase inhibitor.

The onset of Type II diabetes and its associated long-term cardiovascular complications has been linked to persistent postprandial hyperglycemia [18-19].A number of synthetic drugs available for the treatment of Type II diabetes mellitus and mainly work to affect insulin resistance or defective insulin secretion. However, the use of many of these drugs has been associated with side effects, leading researchers to seek safe and natural sources for new therapeutics [20]. Currently, much focus has been based on the dietary sources of $\alpha$-amylase and/or $\alpha$ glucosidase inhibitors to delay the intestinal absorption of digested carbohydrates [21-22]. Alpha-amylase and $\alpha$ glucosidase is also drug design targets for the development of compounds for the treatment of diabetes, obesity, and hyperlipidemia [23].

Here we report the ability of a phenolic enriched extract of I.frutescens to inhibit $\alpha$ - amylase, and $\alpha$-glucosidase. Chemical analysis showed that the major constituents of PPE are flavonoids and simple phenolic compounds. Our results revealed that the PPE was able to inhibit $\alpha$-amylase and $\alpha$-glucosidase activities in vitro in a dose-dependent manner. The different extent of $\alpha$ - amylase inhibitory effects of a polyphenolic extract of I.frutescens were studied by four different methods. The total phenolic contents seemed to be inversely associated with the amylase inhibition. We speculate that Phenolic flavonoids synergies may be involved in the leaves of I. frutescens extract enzyme inhibition mechanism. It has been recently reported that tea polyphenols inhibited glucose transporter of small intestine epithelial cells [24]. In addition, polyphenols controlled the rise in blood glucose level when humans fed with a fixed amount of carbohydrates with food because a negative correlation was indicated by the polyphenolic content and glycemic index [25]. 


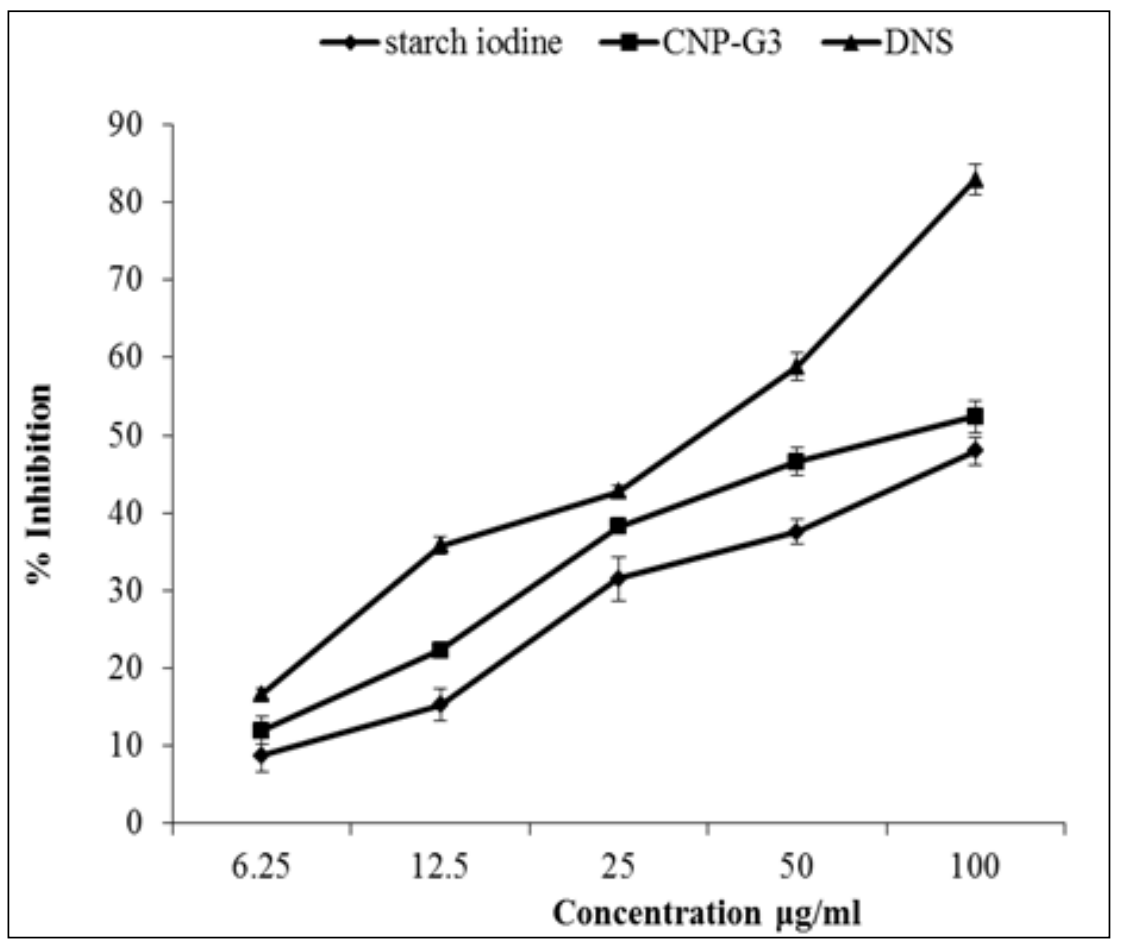

Figure 1. In vitro inhibitory effect of polyphenolic extract of I.frutescens on $\alpha$ - amylase enzyme using starch iodine, CNP-G3 and DNS method. Values are expressed as mean \pm SEM of triplicate experiments.

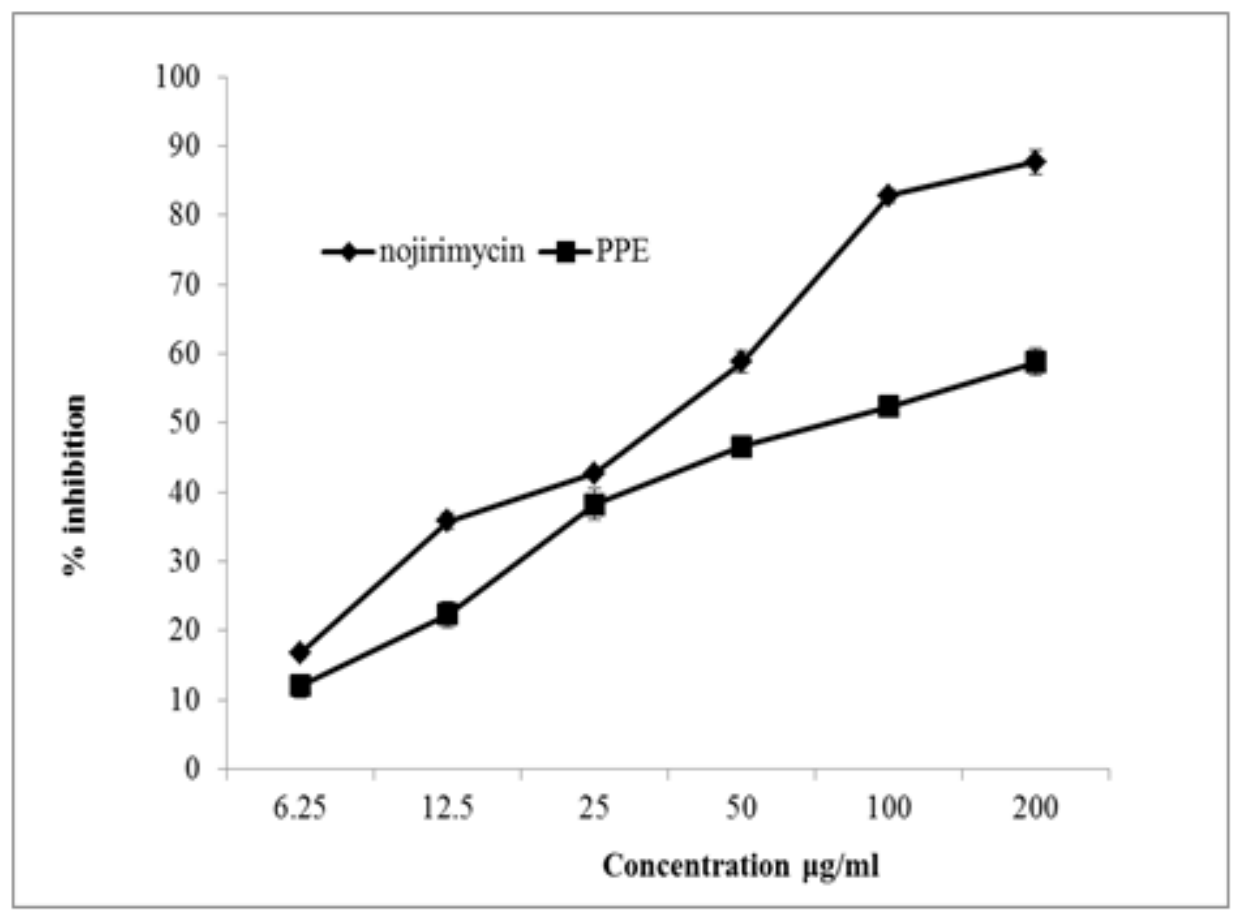

Figure 2. In vitro inhibitory effect of polyphenolic extract of I.frutescens on rat $\alpha$ - amylase enzyme. Values are expressed as mean $\pm \mathrm{SEM}$ of triplicate experiments. 


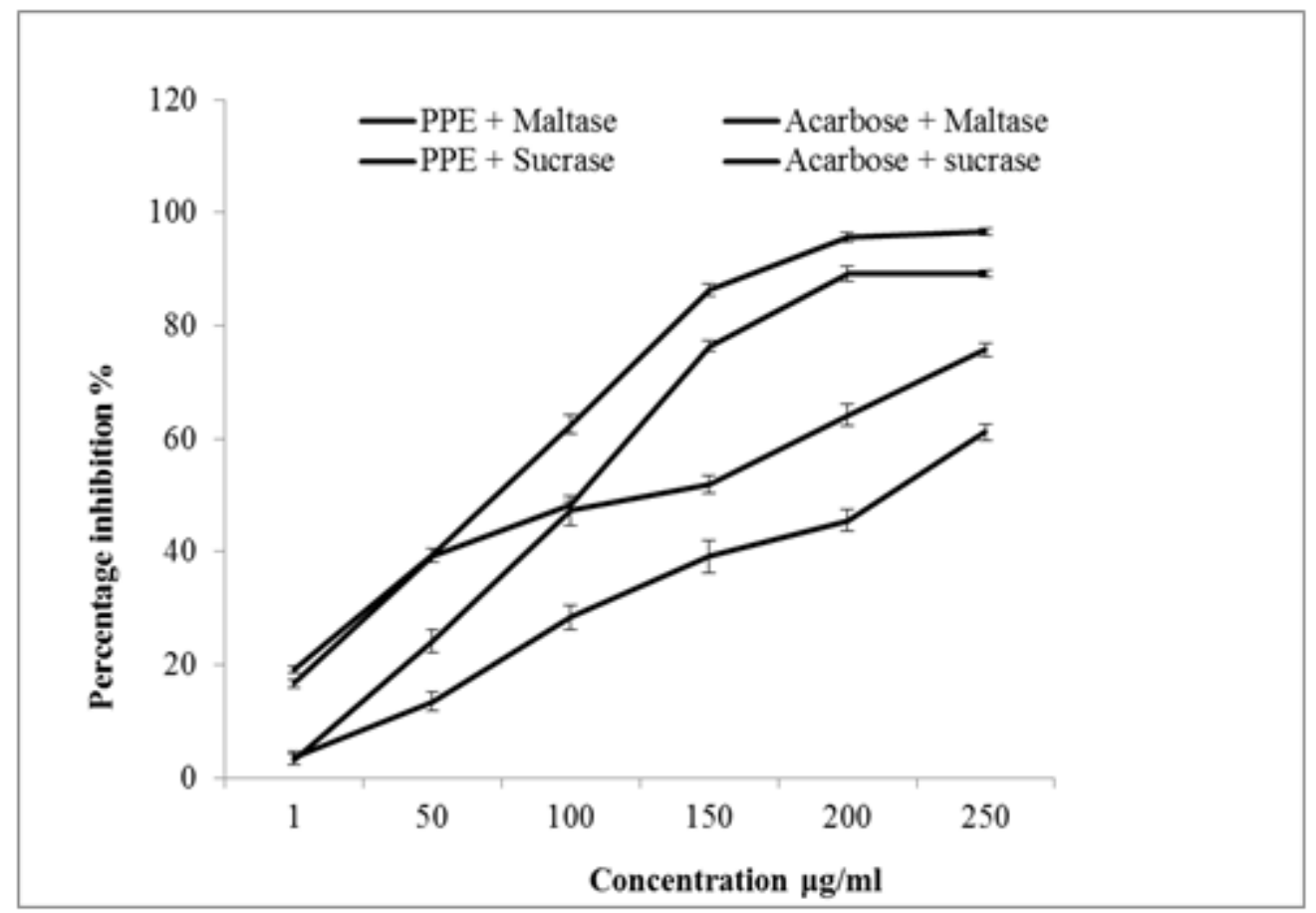

Figure 3. The $\alpha$-glucosidase inhibitory activity of polyphenolic extract and acarbose Values are expressed as mean \pm S.E.M of three experiments. Inhibitory concentration

The enzyme inhibitors impede digestion through their action of digestive enzymes (amylase and glucosidase) which play a key role in the digestion of plant starch. Our results showed moderate inhibition of $\alpha$-amylase activity. Inhibitory activities of PPE against $\alpha$-amylase that our results confirmed suggest its potential in prevention and therapy of obesity and diabetes. Living organisms use enzyme inhibitors as a major tool to regulate glycolytic activities of $\alpha$-amylase. In most of the cases, the mechanism of inhibition occurs through the direct blockage of the active centre at several subsites of the enzyme [26].

Extract and/or purified inhibitors may be used as a drug design target for the treatment of diabetes by exploring their potential pharmacological effects. It is widely recommended that a wide and deep investigation of therapeutic enzyme inhibitors is needed to explore the medicinal values of Indian medicinal plants used ethno-medically for treating diabetes. We hypothesize that the health benefits of I.frutescens against diabetes mellitus may be due to the $\alpha$-amylase and $\alpha$-glucosidase inhibitory activities of the apigenin, luteolin, quercetin and other polyphenolics compounds, which are found within leaves of I.frutescens has been shown in other studies [27]. The in vitro effectiveness of luteolin, quercetin and apigenin on the inhibition of $\alpha$-glucosidase and $\alpha$-amylase have been previously described [28-29]. These compounds may play an important role in controlling dietary glucose uptake in the small intestine by PPE extract, due to its $\alpha$ - amylase, and $\alpha$-glucosidase inhibitory activities.

From the chemical structures and inhibitory activity relationship, poly-hydroxyl groups in the flavonoids seem to play an important role in the inhibition of these enzymes. Since many plant polyphenols are known to form a hydrophobic bond to proteins and would affect the functions of not only $\alpha$-glucosidase but also the $\mathrm{Na}^{+}$-glucose transporter and the $\mathrm{Na}^{+}$-dependent glucose transporter protein as has been shown in the small intestinal epithelium of mice [30]. Food grade phenolic $\alpha$-amylase and $\alpha$-glucosidase enzyme inhibitors from herbal extracts are potentially safer, and therefore may be proffered alternative for inhibition of carbohydrate breakdown and control of glycemic index of food products. It has been reported that $\alpha$-glucosidase inhibitors usually do not alter the total amount of carbohydrate absorbed and therefore do not cause any net nutritional caloric loss although slow down carbohydrate digestion. Our studies suggest a new biological activity of this plant as it may mildly inhibit $\alpha$-amylase and $\alpha$-glucosidase activities, consequently, this may be expected to clinically contribute to the gentle improvement of postprandial hyperglycemia in diabetic patients. Further research is aimed at investigating the potential role of $\alpha$-amylase and $\alpha$-glucosidase inhibitors present in the polyphenolic extract of I.chnocarpus frutescens.

\section{Conclusions}

In conclusion, the outcomes of the current investigation confirm that the polyphenolic extract of I.chnocarpus frutescens is effective against $\alpha$-amylase and $\alpha$-glucosidase, 
which may be useful to decrease the postprandial glucose levels. Isolation of the active phytochemicals is presently being pursued in our research laboratory to better understand the mechanism of this enzyme inhibition. Furthermore, our results support the ethnomedical use of plants in medicine based on their inhibitory activity of carbohydrate absorption from the gut. Only a thorough and full-fledged study can rationalize the use in humans.

\section{List of Abbreviations}

\author{
$\mathrm{PPE}=$ Polyphenol extract \\ $C N P G 3=2$-chloro-p-nitrophenyl- $\alpha$-D-maltotrioside \\ $\mathrm{DNS}=$ dinitrosalicylic acid $\mathrm{KSCN}=$ Potassium \\ thiocyanate \\ $\mathrm{Abs}=$ Absorbance \\ $\mathrm{CNP}=$ 2-chloro-4-nitrophenol \\ CPCSEA $=$ Committee for the Purpose of Control and \\ Supervision of Experiments on Animals \\ $\mathrm{ANOVA}=$ Analysis of variance
}

\section{Conflicts of Interest}

None

\section{Author's Contribution}

$\mathrm{KC}$ designed the study, performed the experiments, did the literature searches, and wrote the manuscript. ET and SRD managed the experimental process and provided technical assistance. Author SCM, RS and VK contributed to the protocol and provided general supervision of the study. All authors have read and approved the submission of the manuscript.

\section{Acknowledgements}

The authors grateful to All India Council of Technical Education (AICTE) for providing financial support in the name of National Doctoral Fellowship to carrying out this work.

\section{Declarations}

Experiments were performed complied with the rulings of the Committee for the Purpose of Control and Supervision of Experiments on Animals (CPCSEA) New Delhi, India and the study was permitted by the institutional ethical committee of the Jadavpur University.

\section{REFERENCES}

[1] B.R. Zimmerman. Postprandial hyperglycaemia: Implications for practice. American Journal of Cardiology 2001, 8(6): 32-36.

[2] V. Fonseca. Clinical significance of targeting postprandial and fasting hyperglycemia in managing type 2 diabetes mellitus. Current Medical Research Opinion 2003, 19(7): 635-641.

[3] S. Mudaliar, and R.R. Henry. New oral therapies for type 2 diabetes mellitus: The glitazones or insulin sensitizers. Annual Review of Medicine 2001, 52(1): 239-257.

[4] M.F. Carrol, A. Gutierrez, M. Castro, D. Tsewang, and D.S Schade. Targeting postprandial hyperglycemia: A comparative study of insulinotropic agents in type 2 diabetes. The Journal of Clinical Endocrinology \& Metabolism 2003, 88(11): 5248-5254.

[5] G.J. Mcdougall, N.N. Kulkarni, and D. Stewart. Current developments on the inhibitory effects of berry polyphenols on digestive enzymes. Biofactors 2008; 34(1): 73-80.

[6] L. Octivio and D. Rigden. Activity of wheat alpha-amylase inhibitors towards bruchid alpha-amylase and structural explanation of observed specificities. European Journal of Biochemistry 2000, 267(8): 2166-2173.

[7] S. Rohn, H.M. Rawel, and J. Kroll. Inhibitory effects of plant phenols on the activity of selected enzymes. Journal of Agricultural Food Chemistry 2002, 50(12): 3566-71.

[8] F.A. Van de Laar. Alpha-glucosidase inhibitors in the early treatment of type 2 diabetes. Vascular Health and Risk Management 2008, 4(6): 1189-1195.

[9] T. Matsui, T. Ueda, T. Oki, K. Sugita, N. Terahara, and K. Matsumoto. $\alpha$-glucosidase inhibitory action of natural acylated anthocyanins. 1. Survey of natural pigments with potent inhibitory activity. Journal of Agricultural Food Chemistry 2001, 49(4): 1948-1951.

[10] J.S. Kim, C.S. Kwon, and K.H. Son. Inhibition of $\alpha$-glucosidase and amylase by luteolin, a flavonoid. Bioscience Biotechnology Biochemistry 2000, 64: 2458-2461.

[11] Z. Han, T. Shen, and H. Lou. Dietary polyphenols and their biological significance. International Journal of Molecular Science 2007, 8(9): 950-988.

[12] M.J. Bhandary, K.R. Chandrashekar, and K.M. Kaveriappa. Medical ethnobotany of the Siddis of Uttara Kannada District, Karnataka, India. Journal of Ethnopharmacology 1995, 47(3): 149-158.

[13] M. Daniel and S.D. Sabnis. Chemo-taxonomical studies on apocynaceae. Indian Journal of Experimental Biology 1978, 16: 512-513.

[14] F.J. Gella, G. Gubern, R. Vidal, and F. Canalias. Determination of total and pancreatic alpha-amylase in human serum with 2-chloro-4-nitrophenyl-alpha-D-maltotr ioside as substrate. Clinica Chimica Acta 1997, 18(1-2):147-160

[15] H. Ali, P.J. Houghton, and A. Soumyanath. $\alpha$-amylase inhibitory activity of some Malaysian plants used to treat 
diabetes; with particular reference to Phyllanthus amarus. Journal of Ethnopharmacology 2006, 107(3):449-455.

[16] K. Kobayashi, N. Funayama, R. Suzuki, and F. Yoshizaki. Survey of the influence of Chinese medicinal prescriptions on amylase activity in mouse plasma and gastrointestinal tube. Biological Pharmaceutical Bulletin 2002, 25(8): 1108-1111.

[17] A. Dahlqvist. A method for the assay of intestinal disaccharides. Anal Biochemistry 1964, 7(1): 18-25.

[18] E. Bonora. Postprandial peaks as a risk for cardiovascular disease: epidemiological perspectives. International Journal of Clinical Practice 2002, S129 (129); 5-11.

[19] M.F. Dicarli, J. Janisse, G. Grunberger, and J. Ager. Role of chronic hyperglycemia in the pathogenesis of coronary microvascular dysfunction in diabetes. Journal of the American College of Cardiology 2003, 41(8): 1387-1393.

[20] J. Tibaldi. Importance of postprandial glucose levels as a target for glycemic control in type 2 diabetes. Southern Mededical Journal 2009;102(1):60-66

[21] F. Ye, Z. Shen, and M. Xie. Alpha-glucosidase inhibition from a Chinese medical herb (Ramulus mori) in normal and diabetic rats and mice. Phytomedicine 2002, 9(2): 161-166.

[22] P.P. Mccue, and K. Shetty. Inhibitory effects of rosmarinic acid extracts on porcine pancreatic amylase in vitro. Asia Pacific Journal of Clinical Nutrition 2004, 13(1): 101-106.

[23] R. Sascha, M.R. Harshadrai, and K. Jurgen. Inhibitory effects of plant phenols on the activity of selected enzymes. Journal of Agricultural Food Chemistry 2002, 50(12): 3566-3571

[24] K. Johnston, P. Sharp, M. Clifford, and L. Morgan. Dietary polyphenols decrease glucose uptake by human intestinal Caco-2 cells. FEBS Letters 2005, 579(7): 1653-1657.

[25] M.J. Amiot, C. Riva, and A. Vinet. Effects of dietary polyphenols on metabolic syndrome features in humans: a systematic review. Obesity Reviews 2016, 17(7): 573-586.

[26] P.M. Sales, P.M. Souza, L.A. Simeoni, and D. Silveira. $\alpha$-amylase inhibitors: a review of raw material and isolated compounds from a plant source. Journal of Pharmacy Pharmaceutical Sciences 2012, 15(1): 141-83.

[27] R.P. Singh and R.P. Singh. Flavonoids of the flowers of Ichnocarpus frutescens. Journal of Indian Chemical Society 1987, 16: 715-756.

[28] A. Shadab, A.K. Rafeeq, J. Subia, and A. Syeda. Report antidiabetic effects of native date fruit aseel (Phoenix dactylifera $L$.) in normal and hyperglycemic rats. Pakistan Journal of Pharmaceutical Sciences 2017, 30(5): 1797-1802.

[29] K. Tadera, Y. Minami, K. Takamatsu, and T. Matsuoka. Inhibition of $\alpha$-glucosidase, and $\alpha$ - amylase by flavonoids. Journal of Nutritional Science and Vitaminology 2006, 52(2): 149-153.

[30] H.C. Hong, S.L. Li, X.Q. Zhang, W.C. Ye, and Q.W. Zhang. Flavonoids with $\alpha$-glucosidase inhibitory activities and their contents in the leaves of Morus atropurpurea. Chinese Medicine 2013, 8(1):19-25. 